Brit. J. industr. Med., 1956, 13, 85.

\title{
ALUMINIUM POWDER INHALATIONS IN THE TREATMENT OF SILICOSIS OF POTTERY WORKERS AND PNEUMOCONIOSIS OF COAL-MINERS
}

\author{
BY \\ M. C. S. KENNEDY \\ From the Medical Research Council Treatment Centre, North Staffordshire Royal Infirmary, Stoke-on-Trent
}

(RECEIVED FOR PUBLICATION DECEMBER 7, 1955)

Haldane in 1918 postulated the theory that the dust of certain mineral rocks had an antidotal effect on the fibrogenic action of siliceous dusts, a theory which has since been put to the test by animal investigators. Kettle in 1932 showed that ironcoated particles of quartz were inert when injected subcutaneously into animals, whereas uncoated quartz caused marked necrosis and cellular change in the subcutaneous tissues. In 1937 Denny, Robson and Irwin found that small quantities of metallic aluminium inhibited the solubility of siliceous material in the beaker, and that quartz particles coated with aluminium failed to produce fibrosis in the lungs of rabbits, whereas particles not so treated caused frank pulmonary fibrosis. Later, in 1939, these three authors working on rabbits showed that the fibrogenic action of quartz could be prevented if $1 \%$ aluminium was given independently of the quartz. Gardner, Dworski, and Delahant (1944) were unable to substantiate Kettle's work using iron oxide, but obtained results with aluminium hydroxide similar to those reported by Denny, Robson, and Irwin.

These experimental findings on laboratory animals gave rise to the hypothesis that human silicosis might be prevented, or progression of the established disease arrested, by the prophylactic or therapeutic inhalation of aluminium powder. Subsequently workers in America and Canada published preliminary findings on the value of aluminium inhalations for the treatment of silicosis, and in 1946 Professor E. J. King and Dr. C. L. Sutherland visited Canada and America to review the whole question of aluminium therapy on behalf of the Medical Research Council. In 1947, after their extensive tour, they reported that although many centres claimed symptomatic improvement with this aluminium treatment there was no definite evidence that aluminium retarded the further development of silicosis, or that it caused regression of the established disease. They recommended that carefully planned and controlled investigations be made into the value of this treatment. This recommendation was endorsed by the Aluminium Subcommittee of the Industrial Pulmonary Diseases Committee, and the present report gives an account of the investigation that was carried out in the Stoke-on-Trent area to evaluate the merits of aluminium inhalations for the treatment of established silicosis of pottery workers and pneumoconiosis of coal-miners. The object was to compare the relative efficacy of aluminium inhalations given in two very different doses (one of which was so low as to be effectively an inert control) in relieving symptoms, in improving the patient's functional capacity, and in retarding the progression of established radiological changes.

\section{Type of Patient}

It was decided that all patients to be included in the trial must (a) have radiological evidence of silicosis or pneumoconiosis associated with a history of exposure to siliceous or coal dusts over a period of at least 10 years; (b) exhibit symptoms caused by the pneumoconiosis; (c) show no evidence of active pulmonary tuberculosis ; $(d)$ show no evidence of cardiovascular disease that might produce symptoms which could be confused with those due to pneumoconiosis; $(e)$ be deemed likely to attend regularly for treatment over a number of years and be willing to submit to all the necessary tests of assessment.

Examination of the first hundred patients to present themselves showed the difficulty of making a confident radiological diagnosis of tuberculosis in the pottery workers and also the high incidence of simple hypertension. Consequently a diagnosis of active tuberculosis was made only if tubercle 
bacilli were found in the sputum or, when the sputum was negative, there was cumulative evidence of active tuberculosis as judged from the E.S.R., radiological, and clinical findings. Since $34 \%$ of the first 100 patients had simple hypertension, i.e., systolic B.P. $>160 \mathrm{~mm}$. $\mathrm{Hg}$ and diastolic B.P. $>$ $90 \mathrm{~mm}$. $\mathrm{Hg}$, patients with simple hypertension were excluded only if they also showed evidence of cardiac enlargement, orthopnoea, and/or clinical evidence of left ventricular failure.

\section{Assessment of Patient}

A detailed initial assessment of each patient was made to cover the industrial history, clinical history, full clinical examination, radiological examination of the chest, a physiological assessment of dyspnoea, and certain laboratory tests. If after the initial assessment the patient was considered suitable for the trial, the quantitative tests were repeated twice at monthly intervals before starting treatment. These repeat pre-treatment assessments were considered necessary to overcome the learning factor in some of the tests and to ensure that the pre-treatment assessment gave a valid picture of the patient's condition. Patients were assessed again after one, two, three, and four years of treatment.

In the assessment of patients before and during treatment particular attention was paid to the following criteria, which were used to determine whether improvement or deterioration occurred.

Clinical Dyspnoeic Grade.-Clinical grading of dyspnoea is notoriously difficult. What a patient is able or unable to do will depend largely on the willingness and practice applied to a particular task. The clinical grading employed was as follows :-

(0) Capable of Heavy Work.

(1) Capable of Moderate Work.-This is defined as dyspnoea confined to heavy exertion; can walk quickly ; can climb low gradients without stopping, can dig, and perform any household duty.

(2) Capable of Light Work.-This is defined as dyspnoea on walking quickly ; can walk up to one mile on the level ; can climb a dozen stairs without undue distress ; can perform all household duties except carrying loads upstairs; can do a little digging in the garden.

(3) Capable of Sedentary Work.-This means dyspnoea on walking at moderate speed on the flat ; can walk up to 500 yards on the level without stopping, and do sedentary work; can assist in light household duties, but unable to do heavier work such as scrubbing floors.

(4) Capable of No Work.-This is dyspnoea on the slightest exertion; patient can just potter around the house.

(5) Total Invalid.-This means dyspnoea at rest.

Symptoms Referable to Pneumoconiosis or Silicosis.-Every year patients were asked whether there was any change in their general condition; cough ; sputum ; dyspnoea ; chest pain, energy, and sleep. Each patient was classified (independently by two observers) as the same, better, or worse in respect of each symptom.

Bronchospasm.-Bronchospasm was assessed by auscultation before and after half a minute of exercise. Patients were classed as having bronchospasm if rhonchi were present or accentuated after exercise whether or not they were present at rest. Bronchospasm was not recorded if no rhonchi were audible after exercise, even if they had been present at rest. Later in the investigation an objective test (Kennedy, 1953) was also employed to assess change in bronchospasm, before and immediately after treatment.

Radiological Appearance of Lung Fields.-The films were classified according to the international classification (Cochrane, Davies, and Fletcher, 1951). Some of the potters' films showed a marked increase in linear striations making classification difficult. Postero-anterior, 12 in. $\times 15$ in., chest films were taken of all patients before starting treatment and again at yearly intervals, and the later films were then compared with the pretreatment films by two observers to assess whether there had been any change.

The Erythrocyte Sedimentation Rate.-Gardner and others (1944) demonstrated that the administration of high concentrations of amorphous hydrated alumina to guinea-pigs influenced unfavourably resistance to tuberculosis. The erythrocyte sedimentation rate was therefore estimated three times before starting treatment and at regular intervals throughout treatment to give early warning of the appearance of active tuberculosis. The E.S.R. was estimated by both the Westergren and Wintrobe methods.

Examination of Sputum for Tubercle Bacilli.Morning specimens of sputum of all new patients were examined by the Staffordshire Public Health Laboratories for the presence of tubercle bacilli by microscopic, cultural, and guinea-pig inoculation methods. Further specimens were examined in this way at weekly intervals (if necessary for several months) if active tuberculosis was suspected.

Physiological Assessment of Ventilatory Function.To obtain an objective index of ventilatory function, 
three tests were employed: The vital capacity (V.C.), the maximum voluntary ventilation (M.V.V.), and a simple exercise tolerance test (E.T.T.). All patients did these tests on three separate occasions before treatment and thereafter at roughly sixmonthly intervals.

The vital capacity and the maximum voluntary ventilation were measured using the procedure described by Gilson and Hugh-Jones (1949). In the exercise tolerance test the exercise ventilation (E.V.) was measured during the last minute of a standard five-minute exercise test as described by Hugh-Jones (1952). The work level was $300 \mathrm{~kg}$. metres per minute ; however, even at this low level no E.V. values could be obtained for many patients as they were unable to complete the five minutes' exercise. Consequently patients have been graded according to their performance during the E.T.T. as shown in Table 1.

TABLE I

NUMERICAL GRADING OF EXERCISE TOLERANCE TEST

\begin{tabular}{|c|c|c|}
\hline Grade & - & $\begin{array}{c}\text { Exercise } \\
\text { Ventilation } \\
(1 . / \mathrm{min} .)\end{array}$ \\
\hline 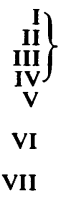 & $\begin{array}{l}\text { Patient completes five minutes } \\
\text { Standard exercise } \\
\text { Patient completes more than three minutes' } \\
\text { exercise but less than five minutes' } \\
\text { Patient completes more than one minute's } \\
\text { exercise but less than three minutes' } \\
\text { Patient unable to complete one minute of } \\
\text { exercise }\end{array}$ & $\left\{\begin{array}{l}25 \text { or less } \\
26-30 \\
31-40 \\
41 \text { or more }\end{array}\right.$ \\
\hline
\end{tabular}

\section{Allocation to Treatment}

Of 300 patients who volunteered for treatment 120 satisfied the selection criteria. These were paired on the basis of sex, occupation (potters and coalworkers), and presence or absence of bronchospasm, and as far as practicable for radiological category, dyspnoeic index, and age. A toss of a coin decided the placing of patients in each pair into treatment group $A$ or $B$. In this way 60 patients were allotted to each treatment group, and these two groups are broadly compared in Table 2.

\section{Treatment Régime}

The apparatus for administration of the dust by inhalation is described in Appendix I. Each group of 60 patients was given aluminium inhalations three times a week. For group A, $50 \mathrm{mg}$. of pure metallic aluminium dust* (provided by the McIntyre Research Foundation) was delivered to the mouth at each treatment. For group B, the dust was carbon

* More than $90 \%$ of this dust was within the respirable size range as measured by means of a selective sampler of the type described by Walton (1954).
TABLE 2

TREATMENT GROUPS A AND B COMPARED BEFORE TREATMENT

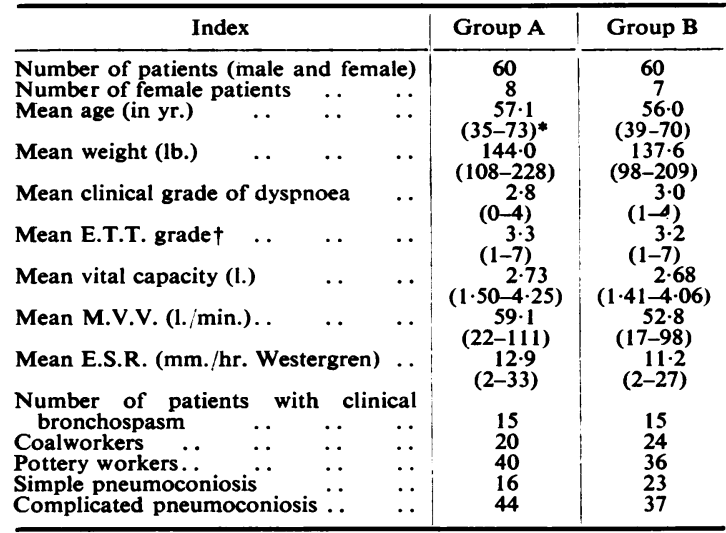

* Figures in brackets indicate the range of values. tOnly 53 group A patients and 55 group B patients attempted the E.T.T.

black with 1 p.p.m. pure metallic aluminium powder added, and $5 \mathrm{mg}$. of this dust was delivered to the mouth. All treatments lasted 15 minutes. Three identical cabinets were made, one for group A patients, one for the group B, and a third for delivering compressed air only. All patients were first given inhalations from this third cabinet for at least six weeks (see below) : if and when they were deemed suitable for the trial they went to the A or B cabinet according to the group to which they had been previously allotted.

Treatment was started in April, 1949, and continued until the end of November, 1952. Sixtyseven of the 120 patients started treatment in April, 1949 , and the remaining 53 joined the trial in small batches at roughly three-monthly intervals over the next two years. Thus, the number of treatments received by a patient depended on when he started treatment and whether or not he continued to attend.

\section{Results}

Lapses.-In a long-term investigation of this type involving elderly and ill patients, it is not surprising that there was a high lapse rate, and Table 3 shows the number of patients falling out at different stages.

At the end of five years, 48 group $A$ and 50 group B patients had been lost during the course of the trial for the different reasons listed. Those falling out because they were "too ill" to attend include the 18 group A and the 17 group B patients who died (analysed later). Most of the patients listed as being " too well" had returned to work and had found further attendance difficult or im- 
TABLE 3

NUMBER OF PATIENTS TO FALL OUT AT DIFFERENT STAGES OF THE INVESTIGATION

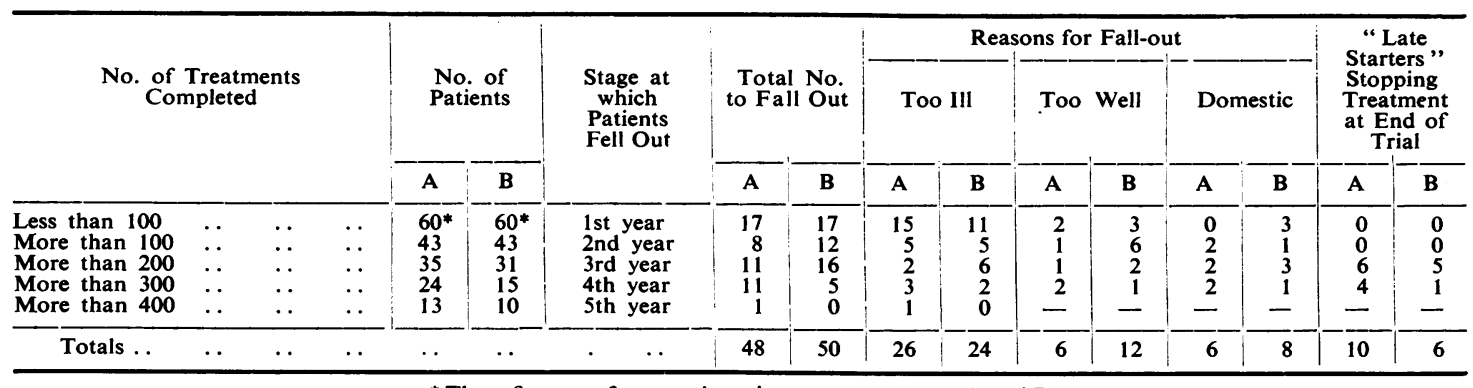

* These figures refer to patients in treatment groups $\mathbf{A}$ and $\mathbf{B}$.

practicable, and those listed as falling out of the trial for "domestic" reasons were in the main patients with increased home responsibilities. The lapse rate, presented in Table 3 , is influenced by the number of "late starters" and of these there were 10 group $A$ and six group $B$ patients attending for treatment when the investigation was concluded.

Presentation of Results. - In Table 3 showing the fate of the 60 patients in each group, it can be seen that 43 patients in each group had at least 101-200 treatments. Thirty-five group A patients and 31 group B patients completed 201-300 treatments, of which 24 and 15 respectively completed $301-400$ treatments, and by the end of the trial there were only 13 group A patients and 10 group B patients who completed more than 400 treatments. In presenting the results it will be considered how patients fared after they had received 101-200 treatments, $201-300$ treatments, $301-400$ treatments, and over 400 treatments, and the findings in the two groups will be compared.

Assessment of Subjective Symptoms after Breathing Air for Six Weeks. - To accustom the patients to the procedure and to obtain an index of the psychological effects, patients received inhalations of pure air for six weeks though they were under the impression that they were receiving aluminium therapy. The first 63 patients were questioned as to whether they had noticed any change in their symptoms. Thirty-six (57\%) stated that they felt definitely better in one way or another, whilst the remaining 27 noticed no improvement.

Number of Treatments.-Table 4 gives the average number of treatments received by patients in each group at the time their progress was reassessed.

Group A attended slightly more frequently and for longer periods than group B; the overall average number of treatments per patient in group $A$ was 324 compared with 274 in group B. The
TABLE 4

NUMBER OF TREATMENTS RECEIVED BY GROUPS A AND B PATIENTS

\begin{tabular}{|c|c|c|c|c|c|c|}
\hline $\begin{array}{l}\text { No. of Treatments } \\
\text { Received }\end{array}$ & $<100$ & $\begin{array}{c}101- \\
200\end{array}$ & $201-$ & $\begin{array}{c}301- \\
400\end{array}$ & $>400$ & $\underset{\text { Average* }}{\text { Overall }}$ \\
\hline $\begin{array}{l}\text { Group } A \\
\text { No of patients } \\
\text { Average number of } \\
\text { treatments per pati- } \\
\text { ent at time of assess- }\end{array}$ & 60 & 43 & 35 & 24 & 13 & - \\
\hline ment $\quad \ldots \quad \ldots$ & 一 & 162 & 246 & 354 & 473 & 324 \\
\hline $\begin{array}{l}\text { Group } B \\
\text { No. of patients } \\
\text { Average number of } \\
\text { treatments per pati- } \\
\text { ent at time of assess- }\end{array}$ & 60 & 43 & 31 & 15 & 10 & 一 \\
\hline $\begin{array}{lll}\text { ment } & \ldots & \ldots\end{array}$ & - & 135 & 239 & 339 & 455 & 274 \\
\hline
\end{tabular}

difference may have been caused by rather more pressure being put on Group A to attend regularly in the later stages of the trial.

Assessment of Patients after 101-200, 201-300, 301-400, and after 400 Treatments. - It has already been shown that the two groups $A$ and $B$ were reasonably comparable at the start of treatment as regards most of the variables (see Table 2).

The mean values of the various indices for the two groups measured after 101-200 treatments, 201-300, 301-400, and more than 400 treatments are given in full in Table 5, from which it is clear that there are no important differences in the behaviour of the two groups.

The patients who had more than 400 treatments were under observation for four years and there were 13 such patients in group A and 10 in group B. The changes of various indices measured for these patients after every 100 treatments are given in Table 6, which again shows no important differences between the groups.

The changes in the individual indices of group $A$ and group B listed in Tables 5 and 6 have been plotted graphically to facilitate comparison of the 
TABLE 5

THE MEAN VALUE OF INDICES AT INTERVALS DURING TREATMENT

\begin{tabular}{|c|c|c|c|c|c|c|c|c|c|c|c|}
\hline \multirow{2}{*}{\multicolumn{2}{|c|}{ Index }} & \multicolumn{2}{|c|}{$\begin{array}{l}\text { Values before } \\
\text { Treatment }\end{array}$} & \multicolumn{2}{|c|}{$\begin{array}{l}\text { After } 100+ \\
\text { Treatments }\end{array}$} & \multicolumn{2}{|c|}{$\begin{array}{l}\text { After } 200+ \\
\text { Treatments }\end{array}$} & \multicolumn{2}{|c|}{$\begin{array}{l}\text { After } 300+ \\
\text { Treatments }\end{array}$} & \multicolumn{2}{|c|}{$\begin{array}{l}\text { After } 400+ \\
\text { Treatments }\end{array}$} \\
\hline & & $\mathbf{A}$ & $\mathbf{B}$ & $\mathbf{A}$ & B & $\mathbf{A}$ & B & $\mathbf{A}$ & B & A & B \\
\hline Number of patients & s.. & 60 & 60 & 43 & 43 & 35 & 31 & 24 & 15 & 13 & 10 \\
\hline Age in years $\dagger$ & . & $57 \cdot 1$ & $56 \cdot 0$ & $56 \cdot 7$ & $56 \cdot 2$ & $56 \cdot 5$ & $56 \cdot 9$ & $57 \cdot 3$ & $59 \cdot 1$ & $56 \cdot 7$ & $59 \cdot 3$ \\
\hline $\begin{array}{c}\text { Weight in lb. : } \\
\text { Before } \ldots \\
\text { After } \ldots \\
\text { Change } . .\end{array}$ & $\begin{array}{l}\cdots \\
\cdots \\
\cdots\end{array}$ & $144 \cdot 0$ & $137 \cdot 6$ & $\begin{array}{r}144 \cdot 5 \\
* 147 \cdot 7 \\
+3 \cdot 2\end{array}$ & $\begin{array}{r}140.6 \\
141.8 \\
+1.2\end{array}$ & $\begin{array}{r}* 146.5 \\
148.7 \\
+2.2\end{array}$ & $\begin{array}{l}140 \cdot 1 \\
140 \cdot 2 \\
+0 \cdot 1\end{array}$ & $\begin{array}{l}143 \cdot 0 \\
146 \cdot 6 \\
+3.6\end{array}$ & $\begin{array}{r}141.4 \\
139.6 \\
-1.8\end{array}$ & $\begin{array}{r}137 \cdot 5 \\
138.9 \\
+1.4\end{array}$ & $\begin{array}{l}137 \cdot 5 \\
137 \cdot 5 \\
\text { None }\end{array}$ \\
\hline 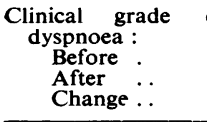 & $\begin{array}{l}\text { of } \\
\ldots \\
\cdots \\
\cdots\end{array}$ & $2 \cdot 8$ & $3 \cdot 0$ & $\begin{array}{r}2 \cdot 7 \\
2 \cdot 8 \\
+0 \cdot 1 \\
\end{array}$ & $\begin{array}{r}2 \cdot 9 \\
3 \cdot 1 \\
+0 \cdot 2 \\
\end{array}$ & $\begin{array}{r}2 \cdot 7 \\
2 \cdot 6 \\
-0 \cdot 1 \\
\end{array}$ & $\begin{array}{r}2 \cdot 8 \\
2 \cdot 75 \\
-0.05\end{array}$ & $\begin{array}{r}2 \cdot 6 \\
3 \cdot 1 \\
+0.5\end{array}$ & $\begin{array}{r}2.8 \\
3.2 \\
+0.4\end{array}$ & $\begin{array}{r}2 \cdot 5 \\
2 \cdot 5 \\
\text { None }\end{array}$ & $\begin{array}{r}2.9 \\
2.9 \\
\text { None }\end{array}$ \\
\hline $\begin{array}{l}\text { E.T.T. grade : } \\
\text { Before } \quad \cdots \\
\text { After } \quad \cdots \\
\text { Change } . \\
\end{array}$ & $\begin{array}{l}\cdots \\
\cdots \\
\cdots\end{array}$ & $3 \cdot 3(53)$ & $3 \cdot 2(55)$ & $\begin{array}{r}2.9(39) \\
3 \cdot 2(39) \\
+0 \cdot 3 \\
\end{array}$ & $\begin{array}{r}2.9(40) \\
3 \cdot 1(40) \\
+0.2 \\
\end{array}$ & $\begin{array}{r}3 \cdot 0(32) \\
2 \cdot 9(32) \\
-0.1 \\
\end{array}$ & $\begin{array}{r}2 \cdot 8(30) \\
3 \cdot 1(30) \\
+0.3 \\
\end{array}$ & $\begin{array}{r}2.6(21) \\
2.1(21) \\
-0.5 \\
\end{array}$ & $\begin{array}{r}2 \cdot 3 \\
2 \cdot 3 \\
\text { None } \\
\end{array}$ & $\begin{array}{r}2.6(12) \\
3.1(12) \\
+0.5 \\
\end{array}$ & $\begin{array}{r}2 \cdot 2 \\
2 \cdot 5 \\
+0 \cdot 3 \\
\end{array}$ \\
\hline $\begin{array}{ll}\text { V.C. }(1 .): \\
\text { Before } \\
\text { After } \quad \ldots \\
\text { Change . }\end{array}$ & $\begin{array}{l}\cdots \\
\cdots \\
\cdots\end{array}$ & $2 \cdot 73$ & $2 \cdot 68$ & $\begin{array}{r}2 \cdot 77 \\
2 \cdot 69 \\
-0.08 \\
\end{array}$ & $\begin{array}{r}2.69 \\
2 \cdot 54 \\
-0.15 \\
\end{array}$ & $\begin{array}{r}2 \cdot 77 \\
2 \cdot 54 \\
-0.23\end{array}$ & $\begin{array}{r}2 \cdot 75 \\
2 \cdot 54 \\
-0 \cdot 21\end{array}$ & $\begin{array}{r}2.75 \\
2 \cdot 39 \\
-0.36\end{array}$ & $\begin{array}{r}2.98 \\
2.61 \\
-0.37 \\
\end{array}$ & $\begin{array}{r}2 \cdot 72 \\
2 \cdot 36 \\
-0 \cdot 36 \\
\end{array}$ & $\begin{array}{r}3 \cdot 11 \\
2 \cdot 62 \\
-0.49 \\
\end{array}$ \\
\hline $\begin{array}{l}\text { M.V.V. (1./min.) : } \\
\text { Before . } \\
\text { After } \quad . \\
\text { Change . }\end{array}$ & $\begin{array}{l}\cdots \\
\cdots\end{array}$ & $59 \cdot 1$ & $52 \cdot 8$ & $\begin{array}{r}62 \cdot 3 \\
59 \cdot 0 \\
-3 \cdot 3\end{array}$ & $\begin{array}{r}54 \cdot 0 \\
55 \cdot 1 \\
+1 \cdot 1 \\
\end{array}$ & $\begin{array}{r}64 \cdot 0 \\
61 \cdot 7 \\
-2 \cdot 3\end{array}$ & $\begin{array}{r}57 \cdot 0 \\
57 \cdot 2 \\
+0 \cdot 2 \\
\end{array}$ & $\begin{array}{r}62 \cdot 6 \\
58 \cdot 3 \\
-4 \cdot 3 \\
\end{array}$ & $\begin{array}{r}65 \cdot 0 \\
66 \cdot 1 \\
+1 \cdot 1 \\
\end{array}$ & $\begin{array}{r}59 \cdot 7 \\
54 \cdot 0 \\
-5 \cdot 7 \\
\end{array}$ & $\begin{array}{r}67 \cdot 9 \\
64 \cdot 4 \\
-3 \cdot 5\end{array}$ \\
\hline $\begin{array}{l}\text { E.S.R. }(\mathrm{mm} . / \mathrm{hr} .) \text { : } \\
\text { Before } \ldots \\
\text { After } \ldots \\
\text { Change } .\end{array}$ & $\begin{array}{l}\cdots \\
\cdots\end{array}$ & $12 \cdot 9$ & $11 \cdot 2$ & $\begin{array}{r}13.0 \\
11.2 \\
-1.8\end{array}$ & $\begin{array}{r}10 \cdot 3 \\
8.5 \\
-1.8\end{array}$ & $\begin{array}{r}12.8 \\
11.8 \\
-1.0\end{array}$ & $\begin{array}{r}10.2(30) \\
10.8(30) \\
+0.6\end{array}$ & $\begin{array}{r}12.1 \\
10.9 \\
-1.2\end{array}$ & $\begin{array}{r}10.9 \\
12.5 \\
+1.6\end{array}$ & $\begin{array}{r}10.8 \\
11.5 \\
+0.7\end{array}$ & $\begin{array}{r}11.4 \\
9.5 \\
-1.9\end{array}$ \\
\hline
\end{tabular}

* The difference in the means between "after" and "before" arises from the altered number in the group. + The figures in this column give the mean age before treatment.

TABLE 6

CHANGE OF INDICES IN RELATION TO TREATMENT IN RESPECT OF 13 GROUP A PATIENTS AND 10 GROUP B PATIENTS

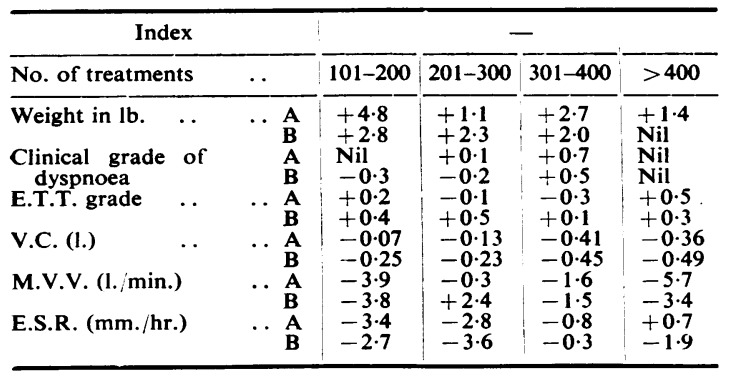

two groups, and the changes in the individual indices are discussed below.

Change in Weight.-From Fig. 1, showing the change in weight, it can be seen that group A showed a small average gain of $3 \mathrm{lb}$. after 100 treatments, and that they maintained a similar gain with further treatment. Group B on the average gained just over $1 \mathrm{lb}$. after 100 treatments but with further treatment dropped back to or below their original average. If the changes in weight during treatment of the 13 group A patients and the 10 group $B$ patients receiving more than 400 treatments be similarly plotted as in Fig. 2, it will be seen that there is nothing to choose between the two groups.

Change in Clinical Grade of Dyspnoea.-Figs. 3 and 4 show that the change in clinical grades of dyspnoea was very similar in both groups. The peak in Figs. 3 and 4 after 301 to 400 treatments is possibly an observer inconsistency since at this stage patients were graded by the author alone who had some knowledge of which patients were in each group. On the other occasions grading was made by two observers, one of whom was without any knowledge of the patient's treatment. This inconsistency emphasizes the importance of having two or more observers and a control group for comparison in a long-term trial of this nature.

Change in Exercise Tolerance Grade.-Fig. 5 shows the grading of patients according to their performance on the exercise tolerance test. There was little to choose between the two groups. Fig. 6 shows that the 12 group A patients (only 12 of the 13 patients were able to do this test) fared rather better than the 10 group B patients up to 300 treatments though the difference was not significant $(p>0 \cdot 50)$. 

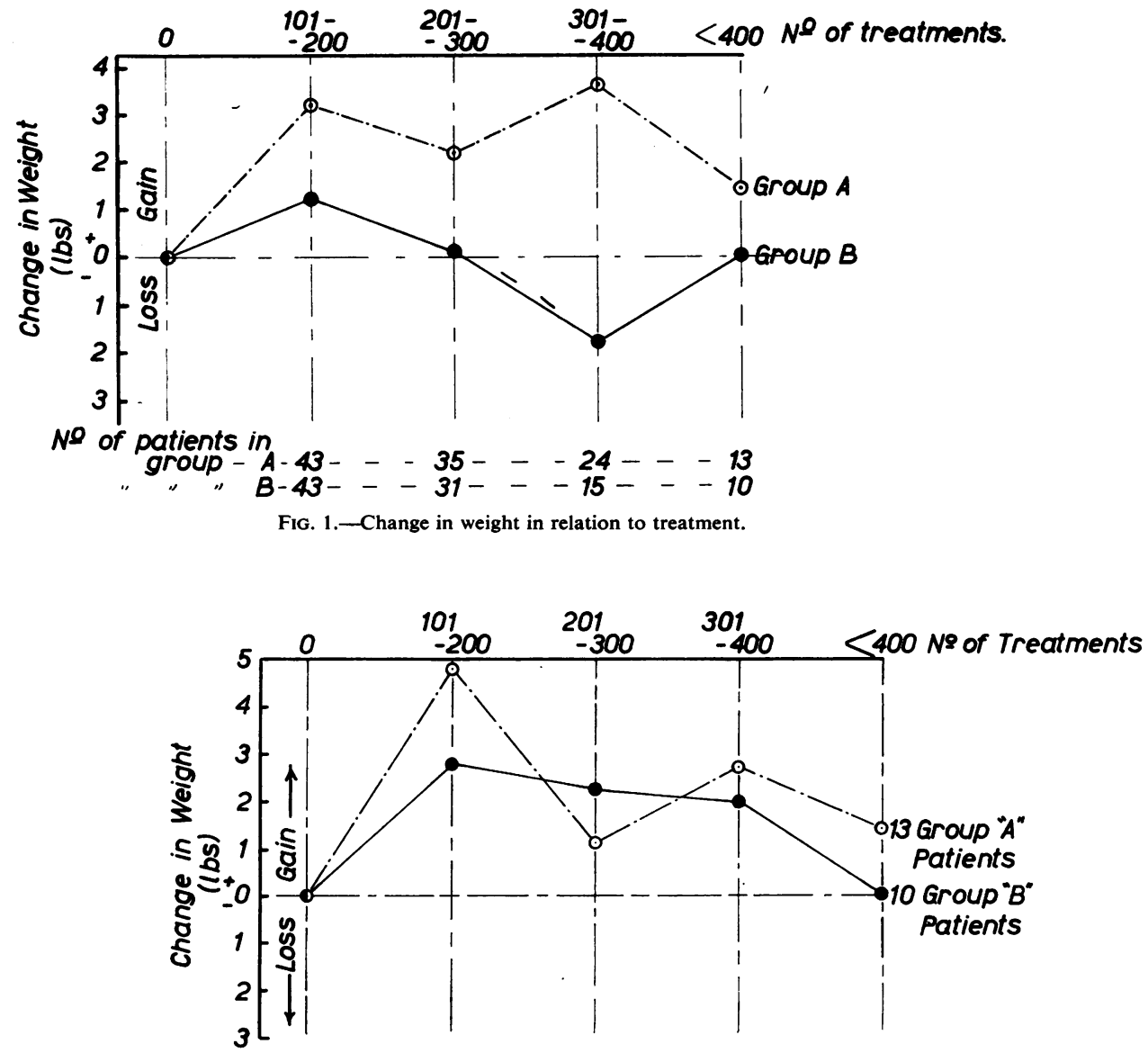

Fig. 2.-Change in weight in relation to treatment.

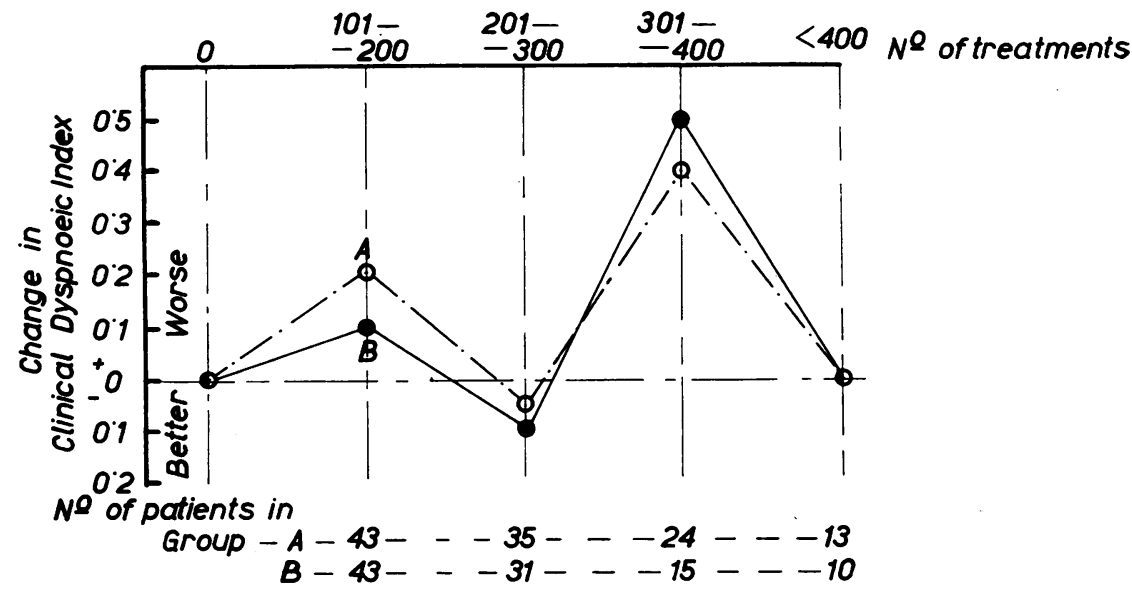

FIG. 3.-Change in clinical grade of dyspnoea in relation to treatment. 
in Relation to Treatment

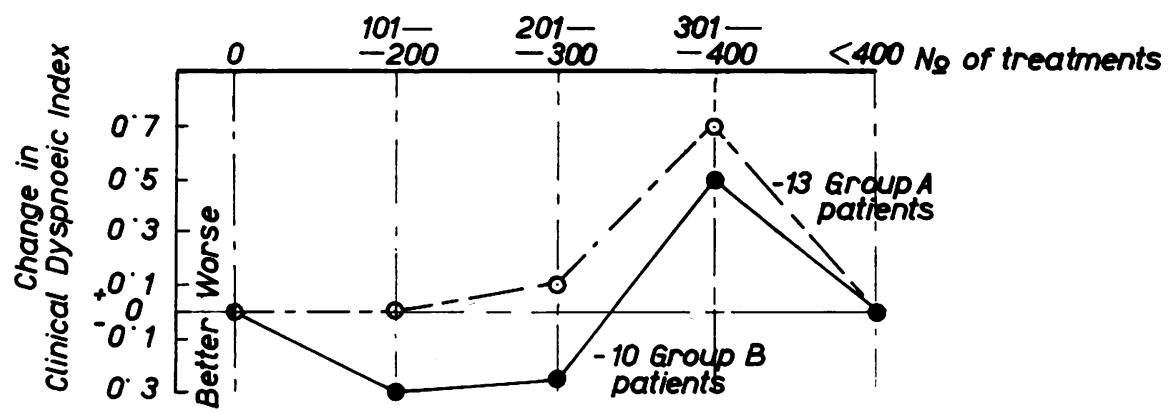

Fig. 4.-Change in clinical grade of dyspnoea in relation to treatment.

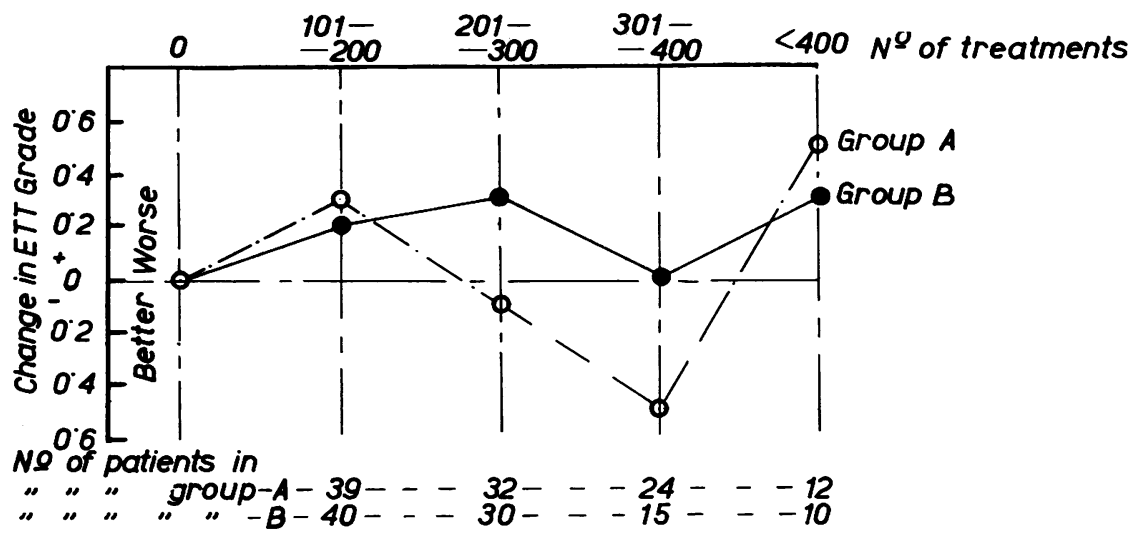

FIG. 5.-Change in exercise tolerance test grading in relation to treatment.

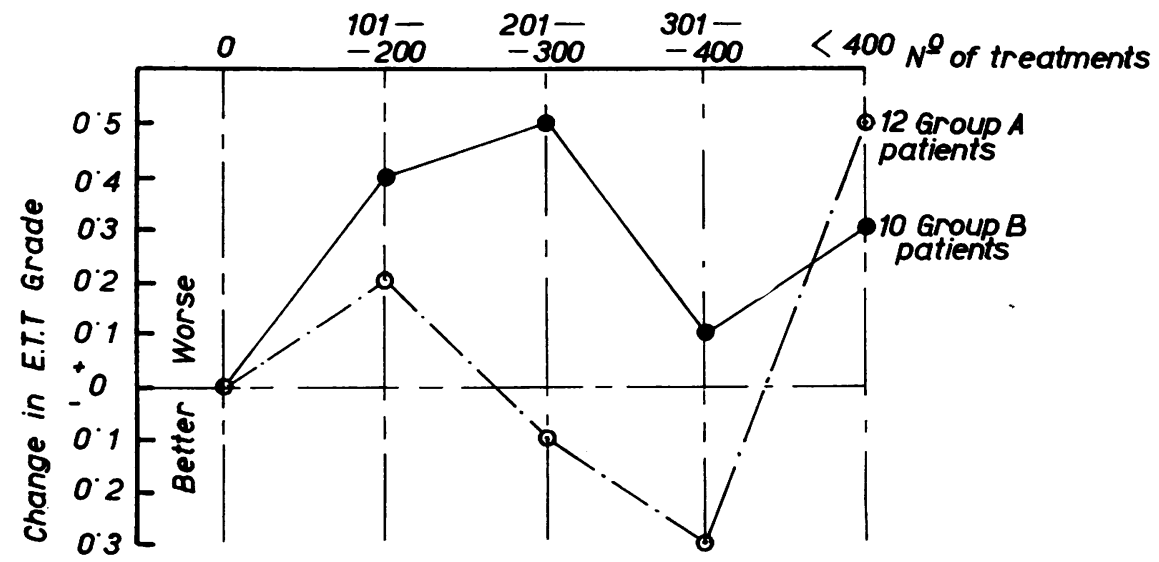

FIG. 6.-Change in exercise tolerance test grading in relation to treatment. 
Change in Vital Capacity.-Three pre-treatment assessments of the V.C. were made at monthly intervals, and analysis of these readings showed that the second reading was $5 \%$ higher and the third $7 \%$ higher than the first reading, which suggests there was a real learning factor to overcome in employing the V.C. on an out-patient basis. The pre-treatment figures recorded in Tables 2,5 , and 6 are those for the third pre-treatment assessment.

Figure 7 shows that the average vital capacity of each group dropped after each hundred treatments by almost exactly the same amount, namely, $100 \mathrm{ml}$. Expressed in another way each group shows an average drop of roughly $100 \mathrm{ml}$. for each year of life. Fig. 8 shows a similar trend in the vital capacity of the 13 group A patients and the 10 group $B$ patients.

Change in Maximum Voluntary Ventilation.Three pre-treatment measurements of the M.V.V., made at monthly intervals, showed that the second reading was $6 \%$ higher and the third $15 \%$ higher than the first reading. Thus there was again a learning effect.

In Fig. 9 it can be seen that group B patients maintain their original M.V.V. values for the first 300 treatments, whereas the group A patients show a small but progressive fall of the order of 1 litre per minute for each 100 treatments. However, by the end of the trial group B patients showed a similar fall. The initial difference in change of M.V.V. is significant $(t=2.283$ for 84 d.f., $0.02<P$ $<0.05)$. During the next hundred treatments the two groups did not change significantly $(t=1.075$ for 64 d.f., $0.30>P>0.20$ ) and in fact changes were almost inversely related to the initial change. When allowance is made for this the mean changes are almost identical $(t=0.050$ for 63 d.f., $P>0.90)$. It appears that subsequent changes add little to the initial findings. The initial drop might be caused by treatment A producing a slightly greater bronchoconstrictor effect than treatment B. However, if the 13 group A patients and the 10 group $B$ patients be compared (Fig. 10) it can be seen that except for the one instance in the 200 treatment level, both treatment groups show a similar change.

Change in Erythrocyte Sedimentation Rate.-The erythrocyte sedimentation rate was measured throughout the investigation in an effort to obtain some index of the infectivity of both groups. Figs. 11 and 12 show that there was little difference between the two groups.

Change in Bronchospasm.--It has been suggested that aluminium inhalations might be helpful in the relief of bronchospasm (Hannon, 1944). In this investigation 15 patients in each treatment group had clinical evidence of bronchospasm at the start of treatment. At the end of a year's treatment only eight of the patients in group $A$ and nine of the patients in group B, who had originally been classed as having bronchospasm, were left in the trial. On re-examination at this time all these patients still had clinical evidence of bronchospasm, and it was found that two further patients in each group had developed bronchospasm. Of the 13 group A patients to complete more than 400 treatments, only one had bronchospasm before treatment, which was still present at the end of treatment, when a further two patients had developed signs of bronchospasm. Of the 10 group $B$ patients to complete more than 400 treatments, only one had bronchospasm at the start of treatment, which was still present at the end of treatment, when no other patient in this group had this complication. These findings suggest that neither treatment A nor B relieved bronchospasm.

Change in Radiological Picture.-The 60 patients in each group were radiographed before the start of treatment and yearly afterwards (or more frequently if changes appeared to be taking place). The follow-up plates taken after the cessation of treatment were compared with the pre-treatment plates. The films of each patient were presented to two observers reading together in a random manner so that they were unaware which was the first or the last films of any particular patient and also to which group they belonged. They reported definite radiological changes in pneumoconiosis in 15 and doubtful changes in 10 sets of films, and changes other than pneumoconiosis in two further patients. The analysis of the joint readings by these two observers is given in Table 7.

TABLE 7

SUMMARY OF RADIOLOGICAL CHANGES

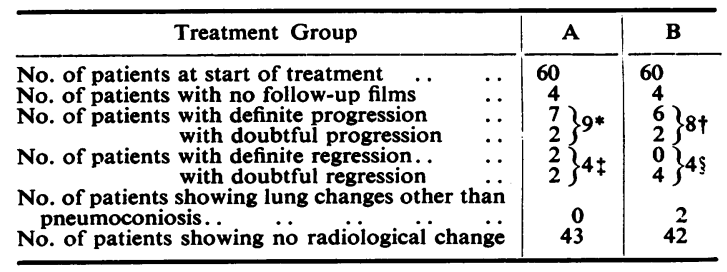

* One coalworker and eight pottery workers.

† Six coalworkers and two pottery workers.

I All pottery workers.

\$ One coalworker and three pottery workers.

The changes were classified into no change, definite and doubtful "progression", or "regression". The progression observed in the nine group $A$ and eight group B patients consisted either in an ex- 


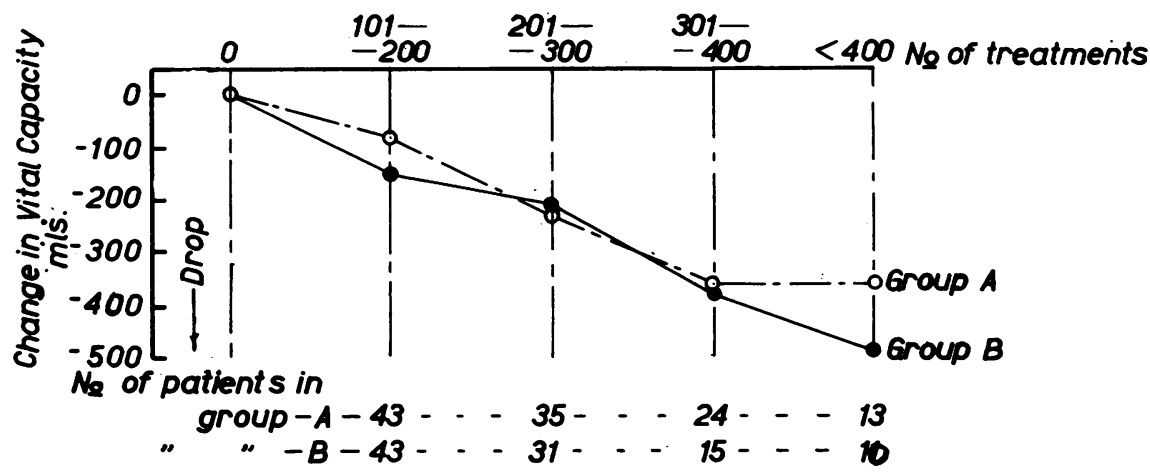

FIG. 7.-Change in vital capacity in relation to treatment.

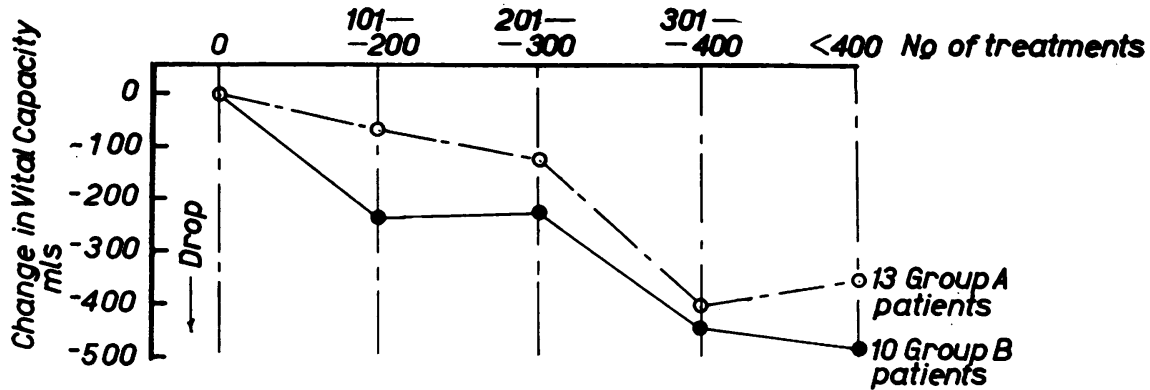

FIG. 8.-Change in vital capacity in relation to treatment.

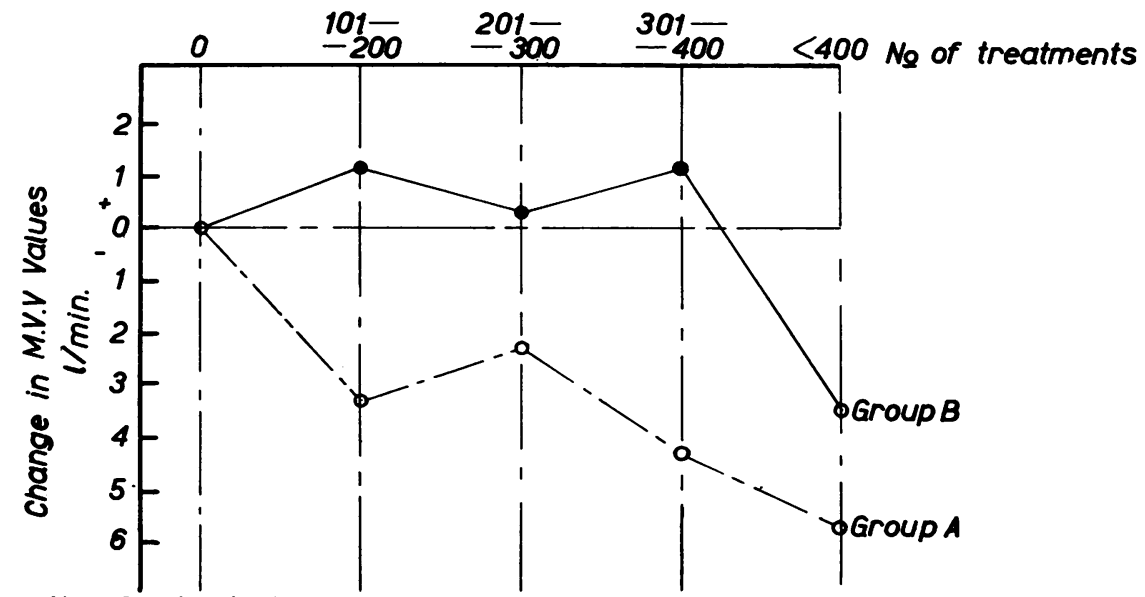

No of patients in

$$
\begin{aligned}
& \text { group-A-43- }-35--24--13 \\
& \text { "B-43- - } 31--15--10
\end{aligned}
$$

FIG. 9.-Change in M.V.V. values in relation to treatment. 


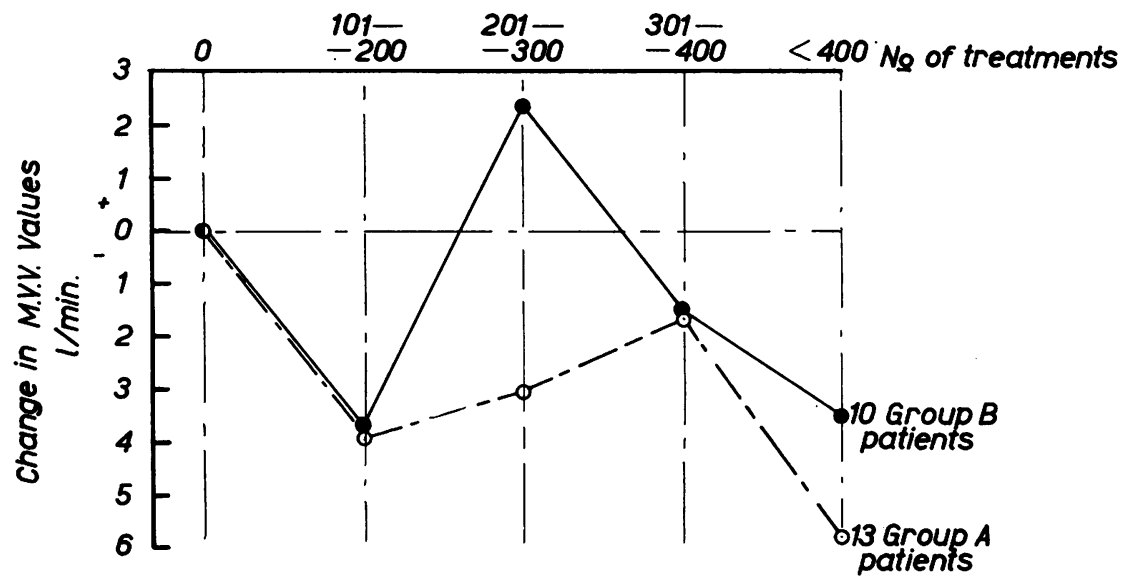

FIG. 10.-Change in M.V.V. values in relation to treatment.

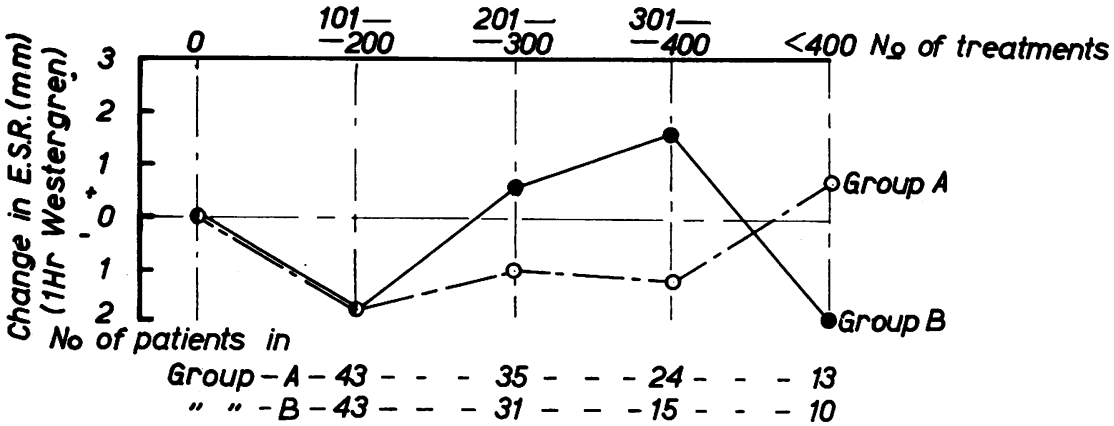

Fig. 11.-Change in erythrocyte sedimentation rate in relation to treatment.

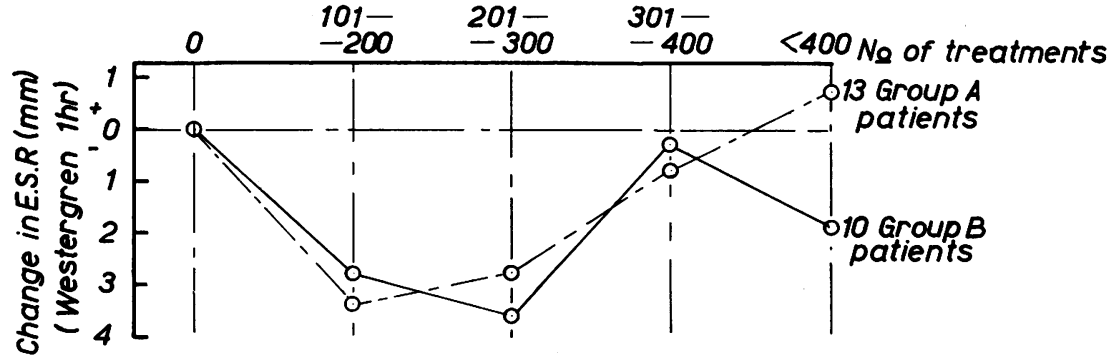

Fig. 12.-Change in erythrocyte sedimentation rate in relation to treatment. 


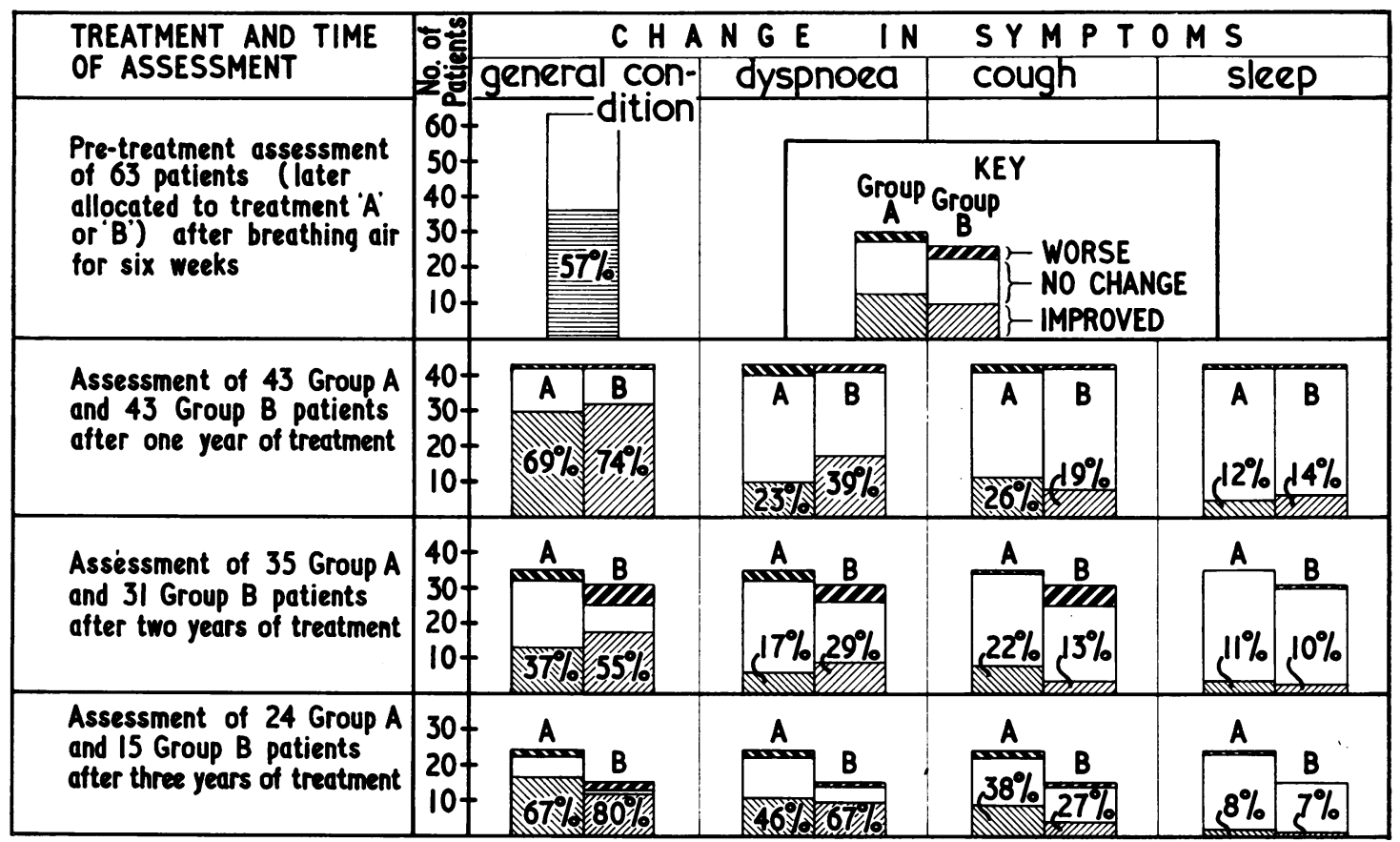

FiG. 13.-Change in patients' symptoms at intervals during treatment.

tension of existing massive fibrosis or the development of new shadows. In those showing radiological progression there was, with the exception of one patient, no change in simple pneumoconiosis.

Four group A and four group B patients were classified as showing doubtful or definite radiological regression : in all these patients the changes were compatible with the natural history of the disease and consisted in a diminution in the size of massive shadows probably due to scarring.

Of the $\mathbf{4 4}$ coalworkers included in the trial, seven were classified as showing progression and one as showing regression after one or more years : the radiological changes that were observed were similar to those described by Davies and Mann (1948) in their follow-up radiological study of coalworkers' pneumoconiosis, and by Fletcher (1945) in his detailed description of the natural history of the disease. In the coalworkers showing radiological progression there was no associated increase in the erythrocyte sedimentation rate and none of them developed open tuberculosis. There were no deaths.

Ten of the 76 pottery workers showed evidence of progression after one or more years. Five of these 10 patients died. The causes of death were bronchial carcinoma (1), congestive heart failure (1), silicosis (1), silicosis and tuberculosis (1), and causes un- known (1). In the 10 pottery workers with radiological progression the E.S.R. increased during treatment to over $20 \mathrm{~mm}$. $/ \mathrm{hr}$. in two patients due to infection which was probably tuberculous. Seven pottery workers were classified as showing radiological regression. Three of these died and the causes of death were congestive heart failure with emphysema and silicosis (1), silico-tuberculosis (1), and causes unknown (1).

Symptomatic Change.-The change in symptoms was assessed by the author and Dr. James Knott independently. Before receiving either treatment but after breathing air alone from the cabinets for six weeks, 63 patients were questioned about their symptoms in an effort to obtain a measure of the probable psychological response: Fig. 13 shows that $57 \%$, i.e., 36 of the 63 patients, claimed improvement in their general condition.

After one, two, and three years of treatment, group A and group B patients were asked whether they were improved, the same, or worse as regards their general condition, dyspnoea, cough, and sleeping. The results are given graphically* in Fig. 13, which shows that there is little to choose between the two groups as regards change of symptoms.

The only symptom that can be checked against

*Tables available on request. 
objective measures is dyspnoea, and in Appendix III the change in this symptom, experienced by the 24 group A and 15 group B patients to receive three years of treatment, is given together with the change in the vital capacity and the maximum voluntary ventilation. It will be seen from this Appendix that there is no general relationship between the subjective findings and the objective measures employed.

Deaths during and after Treatment.-Five years after treatment was started, 18 of the group A patients and 17 of the group B patients had died, and Table 8 shows that the death rate during this period was similar in the two groups.

TABLE 8

NUMBER OF DEATHS OVER FIVE YEARS

\begin{tabular}{|c|c|c|c|c|c|c|c|c|}
\hline \multirow{2}{*}{\multicolumn{4}{|c|}{ Treatment Group }} & \multicolumn{5}{|c|}{ No. of Treatments Completed } \\
\hline & & & & $1+$ & $101+$ & $201+$ & $301+$ & $401+$ \\
\hline A. & $\begin{array}{l}\text { No. of patients } \\
\text { No. dying }\end{array}$ & 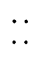 & $\cdots$ & $\begin{array}{l}60 \\
18\end{array}$ & $\begin{array}{r}43 \\
7\end{array}$ & $\begin{array}{r}35 \\
4\end{array}$ & $\begin{array}{r}24 \\
2\end{array}$ & $\begin{array}{r}13 \\
1\end{array}$ \\
\hline B. & $\begin{array}{l}\text { No. of patients } \\
\text { No. dying }\end{array}$ & $\begin{array}{l}\cdots \\
\cdots\end{array}$ & $\begin{array}{l}\cdots \\
\cdots\end{array}$ & $\begin{array}{l}60 \\
17\end{array}$ & $\begin{array}{r}43 \\
8\end{array}$ & $\begin{array}{r}31 \\
6\end{array}$ & $\begin{array}{r}15 \\
1\end{array}$ & $\begin{array}{r}10 \\
0\end{array}$ \\
\hline
\end{tabular}

Thirty-five patients died within five years of starting treatment and in general the pulmonary pathology of those coalworkers and pottery workers who came to necropsy conformed with the general findings of Gough (1947) and Meiklejohn (1949).

Post-mortem reports were obtained for 24 of the 30 patients who died and summaries of these are listed in Appendix II, but histological reports on the lungs are only available for nine patients (three group A and six group B). Pulmonary tuberculosis, coexisting with pneumoconiosis or silicosis, was recorded on five of the 24 post-mortem reports : two were group A patients and three group B patients. Only one patient out of the original 120 patients showed signs of active tuberculosis during life : this patient had been included in the investigation with some misgiving and allotted to group B, and he became sputum positive after some three months of treatment and was excluded from further treatment.

The lungs were obtained for examination in nine of the patients and were examined by Professor $\mathrm{J}$. Gough. It is unfortunate that the lungs of only three patients in group A were obtained for postmortem examination; two were men who only had some 20 treatments with aluminium dust, then lapsed and died two or three years later: on examining these lungs Professor Gough could not find any increase in the aluminium content after staining the lungs with aluminum (Irwin, 1955). Similarly in the third man who had some three years' treat- ment (356 aluminium inhalations), there was no evidence of increased aluminium in the lungs. This finding might be explained by the fact that the man had not received any aluminium treatment for the two years before his death.

The lungs of the six group B patients that were obtained for sectioning did not show any features of special interest.

\section{Discussion}

A number of clinical investigations have been reported in the literature, which suggests that the therapeutic inhalation of aluminium dust is beneficial. Crombie, Blaisdell, and MacPherson (1944), who made the first of these investigations, carried out therapeutic trials on some 30 patients over a period of a year, reasoning that if one could improve patients with silicosis by means of aluminium therapy, then one would expect that aluminium would be effective as a preventive measure. They treated 36 patients and reported that 19 of them were better clinically, though there was no radiological evidence of improvement. Hannon (1944) found symptomatic improvement in 135 men with radiological evidence of silicosis and disability out of a total of 143. He found that following treatment their disability was reduced and that symptoms of cough, tightness of the chest, and general lassitude improved, and that most patients gained weight. Bamberger (1945), studying 49 non-ferrous metal workers, also reported considerable symptomatic improvement in patients treated with metallic aluminium and hydrated alumina. In none of these trials was there an adequate control group.

The trial most comparable to the one reported here was carried out by Berry in 1948, who treated 26 silicotics with aluminium and nine control silicotics with a placebo for roughly 12 months. He found a subjective improvement in both groups, but no objective change in either group, and he concluded that the symptomatic improvement was psychological in origin. The evidence of the present controlled trial fully supports his findings as there is little to choose between groups A and B as regards the changes in any of the indices measured. Over $50 \%$ of patients in both group $A$ and $B$ claimed at nearly all stages of the investigation an improvement in their general condition in one way or another. However, the proportion of patients claiming this improvement was very similar to the proportion claiming improvement after breathing air for six weeks. In Appendix III the change in the mean V.C., M.V.V., and the clinical grade is given for those patients who claimed dyspnoea to be improved, unchanged, or worse after three years of 
treatment. Those patients claiming dyspnoea to be improved had deteriorated slightly more as regards their clinical grading than the patients claiming dyspnoea to be unchanged. The effect is small and probably the result of random errors in the assessments, but it may be the result of a change in attitude to breathlessness or the outcome of a sympathetic approach to their problems during the course of the trial. If this were so, it follows that the accurate assessment of changes in chronic diseases must depend on relevant objective measures. Although in this investigation both groups claimed symptomatic improvement there was no evidence to suggest that group A fared any better than group B as regards improvement of functional capacity, the retardation of the progression of established radiological changes, or expectation of life.

Osmond (1955) has summarized the changes in the physiological assessment of 289 foundry workers given aluminium inhalations over a period of six years. Of the 125 men starting aluminium treatment with functional impairment (using the V.C., M.V.V., maximum tidal volume, and pulmonary reserve as measures), 9\% deteriorated and $90 \%$ were improved after six years. The learning factor, which has been suggested as the cause of the progressive rise in the pre-treatment values of the V.C. and M.V.V. recorded in the present report, may well be responsible for at least some of the improvement described by Osmond. When matters of compensation are at stake, it is only human nature for a patient to be rather slow in learning ! It may be that this learning factor was in part also responsible for the favourable findings described by Hannon (1953) who reported a substantial increase after four months' aluminium therapy in the mean V.C. and M.V.V. values of 46 men which he attributed to the relief of bronchospasm. In the present investigation there was no evidence to suggest that aluminium inhalations relieved bronchospasm, but there was evidence that the expiratory flow rate of patients was reduced immediately following a 15 minutes' inhalation (Kennedy, unpublished data), which is in accord with the suggestion by Lent (1950) that there is often increased bronchospasm following the inhalation of dust.

This trial was designed to show the effect, if any, of aluminium dust inhalation on established cases of pneumoconiosis in potters and coalworkers; from its clear-cut results it cannot be concluded that aluminium dust given prophylactically to men exposed to a quartz hazard will be equally ineffective. King, Wright, Ray, and Harrison (1950) have made further animal investigations using the inhalation technique : one series of rats was exposed to a cloud of quartz with $2 \%$ metallic aluminium powder, and another series was exposed to pure quartz powder. At intervals the animals were killed and the lungs examined. It was found that the animals treated with quartz and aluminium showed evidence of lung fibrosis, but that this fibrosis was only minimal and took much longer to develop than that which occurred in the rats treated with quartz alone. Whatever the reason for the difference between the findings of King and others and those of Denny, Robson, and Irwin (1937), both sets of findings would support the suggestion that aluminium may be valuable for the prophylaxis of silicosis.

A trial of the prophylactic use of the same aluminium dust was started in the Cornish tinmines by the Medical Research Council in October, 1946. Unfortunately, after it had been running some time it was clear that the administrative difficulties of ensuring a satisfactory control group for a sufficient period were insuperable and the trial was stopped.

Recently Hannon (1953), in a trial of aluminium therapy by inhalation lasting over 11 years in a refractory plant, claimed that none of the 11 treated men showed any radiological abnormality whereas 11 of the 12 controls developed "nodulation". However, no details of the dust exposures of the two groups are given. Campbell (1953) in a review of the incidence of certified cases of silicosis that occurred before and after the institution of " change room" aluminium therapy, has also reported evidence in support of the prophylactic theory. Parkinson (1955), reviewing data similar to that reported by Campbell, suggests that aluminium prophylaxis may have been a factor in reducing the silicosis incidence. However, he emphasizes the importance of good ventilation and the vigorous dust control measures that have been continuously improved in the Ontario gold mining area since 1926. It is to be hoped that further reports of the progress of these interesting investigations will include an account of the dust hazard to which the treated and untreated workers have been exposed, both before and during the period of observation and treatment with aluminium.

Gardner and others (1944) reported that the inhalation of high concentrations of aluminium hydroxide in animals unfavourably influenced resistance to tuberculosis, and it was this finding that gave rise to the statement in 1946 by the Council on Industrial Health of the American Medical Association that large amounts of aluminium powder might lower the resistance of patients 
to tuberculosis. For this reason special precautions were taken to exclude from this trial patients who might have coexisting pulmonary tuberculosis. During and after treatment only one group B patient developed open pulmonary tuberculosis, and the analysis of the deaths, the post-mortem reports, the bacteriological reports on the sputa, and the E.S.R. findings provide no evidence to suggest that inhalations of metallic aluminium at the dose level employed in this investigation favour the development of tuberculosis.

\section{Summary and Conclusions}

A controlled trial of aluminium inhalations in the treatment of pottery workers' and coalworkers' pneumoconiosis has been carried out over four years.

One hundred and twenty patients were selected to meet certain criteria and were then separated by pairing into two equal groups comparable as regards age, sex, industrial history, and the manifestations of the disease. The individuals were then randomly allocated to the two forms of treatment.

Group A received pure metallic aluminium dust and group $B$ pure carbon (powder) with the addition of 1 p.p.m. pure metallic aluminium powder. Both groups were given 15-minute inhalations three times each week for as long as three and a half years (or for such less time as the patient continued in the trial).

All subjects were assessed before treatment and during the first, second, third, and fourth years of treatment, and were found to run a parallel course. A major proportion of both groups claimed symptomatic improvement, but the number was only slightly more than those claiming improvement after breathing (unknown to the patient) pure atmospheric air from the cabinets for six weeks. There was no regression of the radiological picture, nor was there objective evidence of improvement in the functional capacity of patients as judged from the results of the exercise tolerance test, the vital capacity, and the maximum voluntary ventilation.

Although there was symptomatic improvement of a general nature in both groups, it is concluded that this improvement was mainly psychological in origin and that the specific inhalation therapy did not produce either any regression in the established disease or an improvement of the patients' functional capacity.

There was no evidence that the aluminium inhalations favoured the development of pulmonary tuberculosis in patients with coalworkers' or pottery workers' pneumoconiosis.
The Industrial Pulmonary Diseases Committee of the Medical Research Council have considered Dr. Kennedy's report on his controlled trial of aluminium therapy and agree with his conclusion that the treatment had no effect either on the symptoms or on the radiological progression of silicosis and pneumoconiosis. They do not recommend the adoption of this method of treatment.

It would have been impossible to launch and complete a long investigation of this type without much help from many sources and people. I should particularly like to thank members of the Aluminium Sub-Committee for encouragement and criticism, and also members of the Pneumoconiosis Research Unit for help in many ways, but particularly Dr. B. M. Wright for devising the means of administering aluminium powder and for his contribution to this report; Dr. J. C. Gilson and Dr. P. Hugh-Jones for advice on the physiological tests, and Mr. P. D. Oldham for statistical help; Drs. A. L. Cochrane, Idris Davies, T. W. Davies, C. M. Fletcher, R. E. Steiner, and A. C. Penman for reading $x$-ray films ; the Board of Governors of the North Stafford Royal Infirmary for providing accommodation for the Treatment Centre; the staff of the North Stafford Royal Infirmary for their constant help, but in particular Dr. A. J. McCall, Dr. D. C. Thursby-Pelham, and Dr. Bellamy and Mrs. Mosely; also Colonel R. Phease, Director of the Medical Research Council's Public Health Laboratories, Stafford; Professor J. Gough, of the Welsh National School of Medicine, for pathological investigations; Dr. A. Meiklejohn and Dr. W. W. Jones, of the Stoke-on-Trent Pneumoconiosis Medical Panel, for advice concerning silicosis in pottery workers ; Dr. J. Knott for his clinical assessments at yearly intervals ; Mr. T. E. Bromley, S.R.N., charge nurse, and Mr. L. Drury, Secretary to the Treatment Centre ; the Potters Insurance Co. Ltd., and the National Union of Pottery Workers for their practical help in initiating the Treatment Centre ; the McIntyre Research Foundation for supplies of aluminium powder.

Additional Tables of detailed results may be obtained from the Director, Pneumoconiosis Research Unit, Llandough Hespital, near Penarth, Glamorgan.

\section{REFERENCES}

Bamberger, P. J. (1945). Industr. Med. Surg., 14, 477.

Bamberger, P. J. (1945). Industr. Med. Surg., 14,

Campbell, A. D. (1953). Proc. Sth Conference of McIntyre Research Foundation, Ontario, Canada.

Cochrane, A. L., Davies, I., and Fletcher, C. M. (1951). British Journal of Industrial Medicine, 8, 244.

Council on Industrial Health, American Medical Assoc. (1946). J. Amer. med. Ass., 130, 1223.

Crombie, D. W., Blaisdeli, J. L., and MacPherson, G. (1944). Canad. med. Ass. J., 50, 318.

Davies, I., and Mann, K. J. (1948). Proc. 9th Int. Congr. industr. Med., London, 1948 , p. 769. Wright, Bristol.

Denny, J. J., Robson, W. D., and Irwin, D. A. (1937). Canad. med. Ass. J., 37, 1 .

,,,,--- , (1939), Ibid., 40, 213.

(1948). Brit. med. J., 1, 1015, 1065.

Gardner, L. V., Dworski, M., and Delahant, A. B. (1944). J. industr. Hyg., 26, 211.

Gilson, J. C., and Hugh-Jones, P. (1949). Clin. Sci., 7, 185.

Gough, J. (1947). Occup. Med., $4,86$.

and Wentworth, J. E. (1949). Proc. 9th Int. Congr. industr. Med., London, 1948, p. 661. Wright, Bristol. 
Haldane, J. S. (1918). Trans. Inst. Min. Engrs. (Lond.), 55, 264. Hannon, J. W. G. (1944). Trans. Canad. Min. Inst. (Inst. Min. Metall.),

47, 180 .
(1953). Proc. 5th Conference of McIntyre Research Foundation on Silicosis.

Hugh-Jones, P. (1952). Brit. med. J., 1, 65.

Hugh-Jones, P. (1952) Brit. med. J., 1, 65.
Irwin, D. A. (1955). Arch. industr. Hlth, 12, 218.

Kennedy, M. C. S. (1953). Thorax, 8, 73.

Kettle, E. H. (1932). J. Path. Bact. 35, 395.
King, E. J., Wright, B. M., Ray, S. C., and Harrison, C. V. (1950). British Journal of Industrial Medicine, 7, 27.

Lent, H. (1950). Beitz. Silikose-Forsch, 10, 3.

Meiklejohn, A. (1949). British Journal of Industrial Medicine, 6, 230.

Osmond, L. H. (1955). Arch. industr. Hlth, 12, 221.

Osmond, L. H. (1955). Arch. industr.

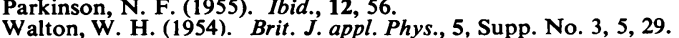

Walton, W. H. (1954). Brit. J. appl. Phys., 5, Supp. No. 3, 5, 29.

Wright, B. M. (1950). J. sci.'Instrum., 27, 12.

\section{A P P E N D I X I}

\section{Administration of Aluminium Aerosol}

\section{By B. M. Wright}

A review of the previous methods for administering dust by inhalation suggested that none of them was entirely satisfactory. Tumble mills are inconvenient and noisy ; also methods in which previously prepared dust was dispersed into chambers were inconvenient owing to the size of the chamber necessary to store the volume of aerosol required, and to allow a number of men to breathe in and out without building up an undue carbon dioxide tension. Both methods also suffered from the disadvantage that it was difficult to control the dose administered with sufficient accuracy.

Use was therefore made of a technique developed for exposing animals for long periods to controlled concentrations of airborne dust (King and others, 1950), in which dust is fed by means of a special mechanism (Wright, 1950) into an air stream which is blown into a chamber. This gives satisfactory control of concentration and a supply of fresh air for breathing.

Since it would not be convenient to use a chamber large enough to contain the men, a small cabinet with breathing tubes and mouthpieces was used. To prevent large changes of pressure which would result if all men inhaled simultaneously, the chamber was fitted with a spirometer bell, which gave it a variable capacity.

The arrangement is shown diagrammatically in Fig. 1. The apparatus consists of a cylindrical container (1) of galvanized iron with a detachable conical top (2). On the top of the cone is fixed a platform (4) on which rests a dust-feed mechanism (3) with its nozzle protruding through the platform. The mechanism is connected to compressed air by a rubber pipe (5), and to a 200 volt A.C. by the lead (6). Four outlet nozzles (7) in the sides of the cylinder are connected by means of lengths of concertina tubing (9) to rubber mouthpieces (10), which are fitted with valves so that the subjects can only inhale from the chamber, and exhale to the outside air. Thus the cabinet is not liable to be contaminated, and the mouthpieces and valves can be removed and sterilized. The lower part of the cylinder is filled with water and an air outlet (11) protrudes above the water level ; this is covered with a galvanized iron bell (12) suspended by a string (14) from a grooved pulley (13). The weight of the bell is taken by a helical spring (15) secured to the fixed axle round which the pulley rotates. The tension of the spring is adjusted so that the bell comes to rest at the middle of its range, but can be moved through the whole of its range without producing any appreciable resistance to breathing.

The apparatus is mounted on a ring stand (16) fitted with three castor wheels (17). As the appearance of the dust feed mechanism differed slightly according to the composition of the dust administered, a metal cover (18) was placed over it to conceal it.

In use, air was blown in through the mechanism at 401 . $/ \mathrm{min}$., and escaped through the nozzles (7) to the mouthpieces. This rate of flow was sufficient for the average respiratory volumes of four subjects. Fluctuations in air consumption were absorbed by the bell.

The apparatus and its method of use are shown in Fig. 2.

The rate of feed of the mechanism (for the treatmen

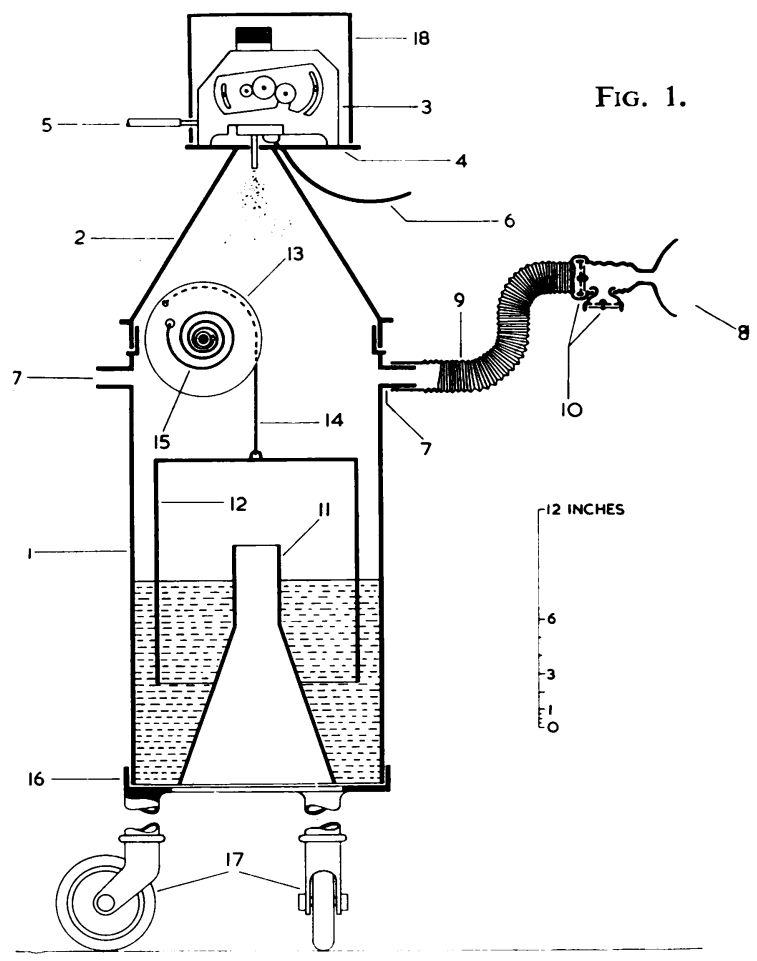




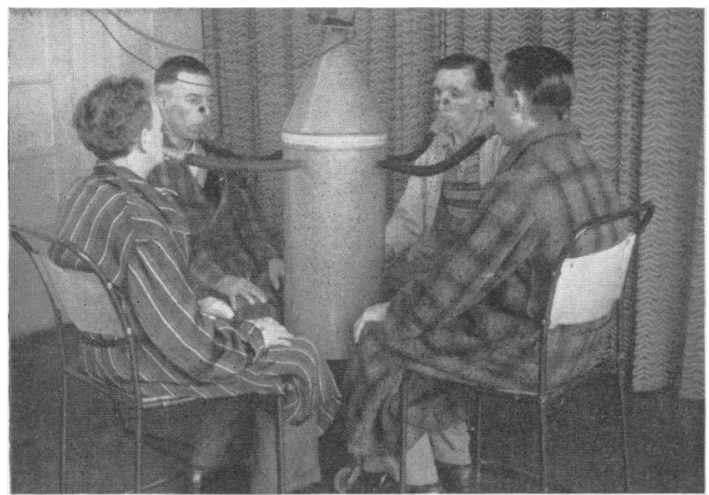

FIG. 2.

of group A patients) was adjusted by trial and error until a filter paper sampler, aspirating at $10 \mathrm{l} / \mathrm{min}$. through the inlet valve of a mouthpiece, collected on the average $50 \mathrm{mg}$. of dust in 15 minutes. Once the mechanism was set it was found possible to check the concentration sufficiently accurately by means of a filter paper and hand pump (Watson and Hounam, 1948), using visual assessment of stain intensity.

The compressed air was supplied by means of a Northey rotary blower, operating without lubrication of the compression chamber, at a pressure of $15 \mathrm{lb}$./sq.in. This discharged into a reservoir of about $2 \mathrm{cu}$. ft. capacity, filled with water cooling coils to condense moisture. The reservoir was connected through a short length of rubber hose (to prevent transmission of noise) to piping in the room where there were three air points, each with a flowmeter and control valve.

The whole arrangement worked well over a period of 42 months, with on the average about 150 quarter-hour treatments every week. The dust-feed mechanisms gave no trouble with aluminium dust, though they worked rather less well with the mixed carbon dust and aluminium, probably because of the lower feed rate.

\section{A P P E N D I X I I}

SUMMARY OF POST-MORTEM FINDINGS IN GROUPS A AND B

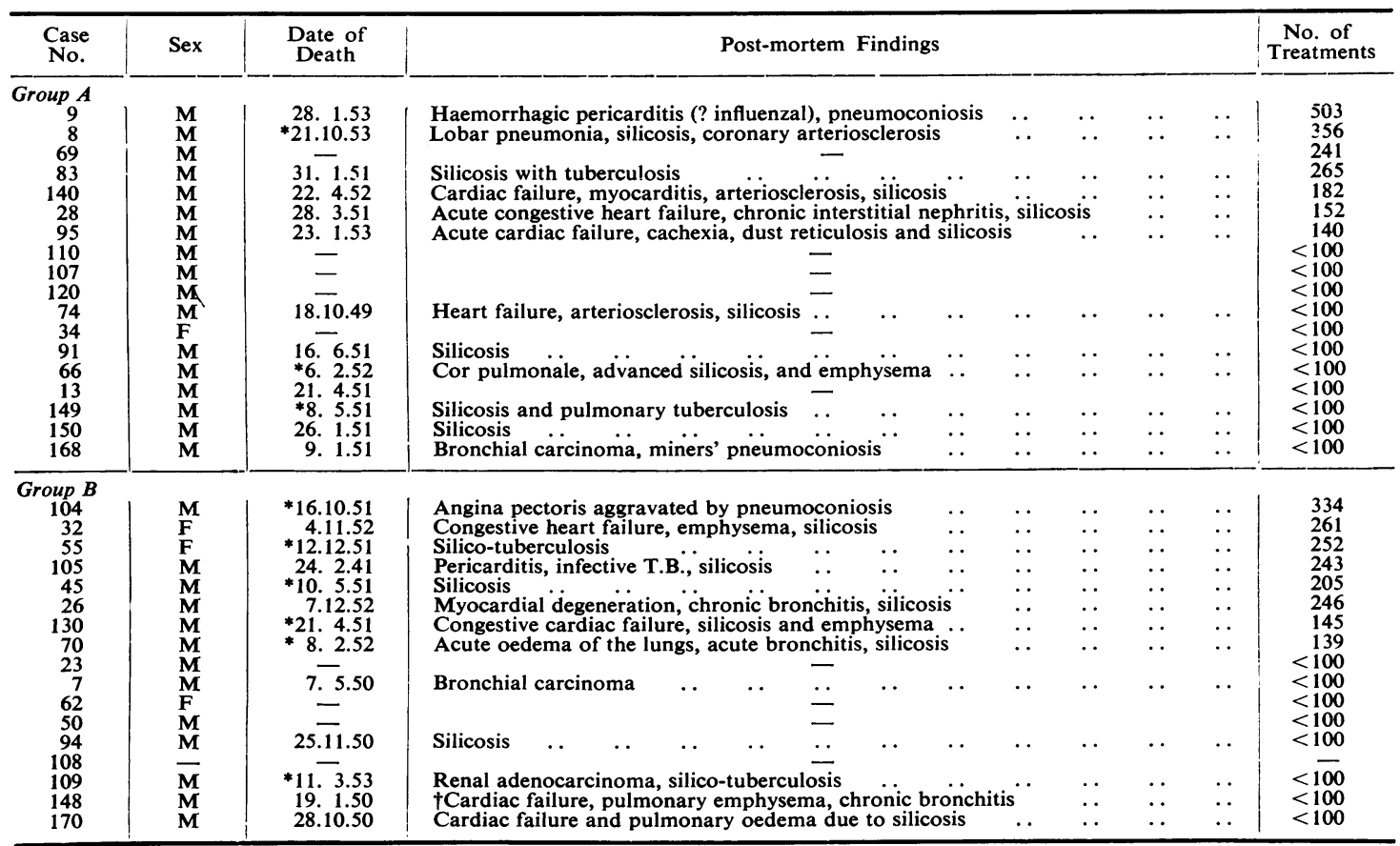

* Lungs obtained for examination. + Bronchiectasis—chronic right aortic valvular disease. 


\section{A P P E N D I X I I I}

\section{Symptomatic Change Related to Change in M.V.V., V.C., and Clinical Grade after Three Years' Treatment}

The summary (Table) of average changes shows that after three years of treatment those patients who claimed that their dyspnoea had improved had deteriorated most on the basis of clinical grading. Conversely, those who claimed that their dyspnoea was worse had, on the basis of clinical grading, deteriorated least.

As regards the changes that occurred in the M.V.V. and V.C. values, there is little to choose between patients claiming improvement of dyspnoea and those claiming no change, though there is a comparatively greater drop in the M.V.V. and V.C. values of those claiming dyspnoea to be worse.
The five women irrespective of their subjective symptomatic change showed an average increase of $6.9 \mathrm{l} . / \mathrm{min}$. in the M.V.V., but very little change in the V.C. and clinical grade of dyspnoea. These findings, which are at variance with the general downward trend of the M.V.V. and V.C. with advancing age as shown by Gilson and Hugh Jones (1949) and in this report, probably reflect the greater reluctance of women to undergo assessment on a spirometer and hence the longer time they require to learn to perform the tests effectively.

AVERAGE CHANGE IN VALUES AFTER THREE YEARS' TREATMENT RELATED TO DYSPNOEA

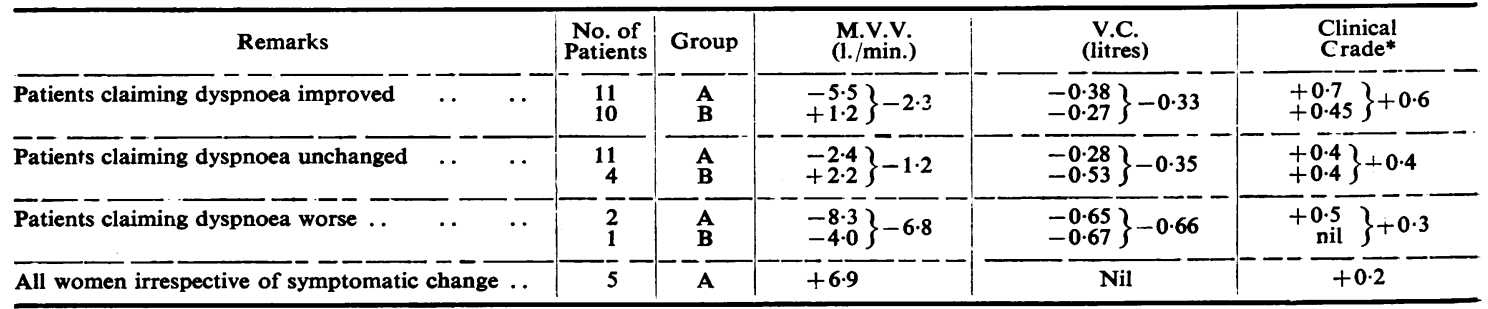

* An increase in the clinical grading indicates deterioration. 